\title{
Perbaikan Manajemen Reproduksi Kambing Peranakan Etawah Melalui Sosialisasi dan Pelatihan kepada Kelompok Ternak Subur Kokap Kulon Progo DIY
}

\author{
Muhammad Rosyid Ridlo \\ Program Studi Kesehatan Hewan, Departemen Teknologi Hayati dan Veteriner, Sekolah \\ Vokasi, Universitas Gadjah Mada \\ Email: rosyidridlo@ugm.ac.id
}

\begin{abstract}
Abstrak
Sosialisasi Manajemen Reproduksi Kambing PE di Kelompok Ternak Subur. Hargo Tirto. Kokap. Kulon Progo. Daerah Istimewa Yogyakarta dilakukan dengan fokus pada permasalahan reproduksi kambing PE. Hal pokok yang harus diutamakan dalam peternakan kambing perah adalah reproduksi. Manajemen reproduksi ternak perah yang bagus sangat berdampak positif pada produksi susu. Latar belakang Kelompok Ternak Subur berada di daerah pegunungan, bermata pencaharian utama sebagai pengrajin gula kelapa. Kelompok ternak Subur masih tergolong pemula dalam beternak. Peternak belum memiliki kemampuan dan pemahaman yang baik terutama mengenai reproduksi. Hal tersebut di atas yang mendasari diadakannya kegiatan pengabdian kepada masyarakat di Kelompok Ternak Subur. Kegiatan penyuluhan dan pelatihan dilaksanakan dengan memberikan sosialisasi dalam bentuk presentasi kepada kelompok ternak dan dilanjutkan diskusi bekaitan manajemen peternakan. Penjelasan spesifik dan praktek pengamatan gejala estrus juga dilakukan untuk meberikan pengetahuan secara langsung. Pemberian bantuan pakan, obat-obatan dan mineral sebagai pakan tambahan untuk kambing PE. Capaian kegiatan ini memberikan dampak positif terhadap kelompok ternak antara lain peternak sudah dapat melakukan dan memahami teknik deteksi birahi yang sangat bermanfaat pada peternakan. Peternak mampu mempraktekkan pengamatan estrus secara visual serta menggunakan bantuan detektor birahi alami. Peningkatan kejadian perkawinan alami meningkat dengan disertai peningkatan kebuntingan pada ternak Kambing Etawah.
\end{abstract}

Kata Kunci : Kambing Etawah, Kelompok Ternak, Manajemen Reproduksi, Pengamatan Birahi.

\begin{abstract}
Reproduction management Socialiszation to "Subur" Perananakan Etawah (PE) Goat Farmer Comunitee in Hargo Tirto, Kokap, Kulon Progo, Yogyakarta was focused on reproduction problems in PE Goat. The main issue that should be priority is Goat Reproduction. Good Dairy goat management reproduction will give positive effect to success of milk production. The back ground of animal husbandary comunitee is located in mountain range of Kulon Progo, their main job activity are as a coconut sugar farmer. The Subur Animal Husbandary Comunitee is grouped as a new dairy goat farmer. They still trying to learn how to develop their husbandary, do not have adequate knowledge of good management farming and good information about reproduction. That condition are the reasons to choose Subur Animal Husbandary Comunitee as a target for Socialiszation in presentation and discussion to farmers. Specific explanation and direct practice in field and does oestrus observation. Distribution of feed, medicine, vitamin and mineral were given to Subur Animal Husbandary Comunitee. The results of this program give many positive impact to the farmers and dairy goats such as; the farmers understand and be able to detect signs of oestrus which is very important to them, the farmers have apply detection of oestrus by visual and buck as a natural oestrus detector, natural mating and pregnant occurrence increased after the farmers have applied oestrus detection in does of PE Goat.
\end{abstract}


Key Word : Animal Husbandary Comunitee, Etawah Goat, Oestrus Detection, Reproduction Management.

\section{PENDAHULUAN}

Pengabdian kepada masyarakat di Kelompok Ternak Subur. Hargotirto. Kokap. Kulon Progo. DIY merupakan kegiatan yang menitikberatkan pada membangun pemahaman tentang beternak kambing Peranakan Ettawa (PE) dan menjaga semangat peternak untuk senantiasa mengembangkan diri. Kelompok ternak Subur merupakan kelompok ternak yang masih belum lama dibentuk dan belum memahami secara menyeluruh bagaimana beternak yang baik. Kesibukan warga berkebun mencari gula aren membuat peternakan kambing sebagai kegiatan sambilan yang belum mendapat perhatian yang banyak dari peternak. Sehingg penanganan dan pemeliharaan ternak kambing masih sebagai kegiatan sampingan. Namun demikian peternak masih bersemangat untuk menimba ilmu dan mengembangkan diri demi keberhasilan peternakan kambing perah Peranakan Etawah.

Salah satu ras kambing perah yang ada di Indonesia adalah Kambing PE. Kambing ini merupakan hasil silang antara kambing lokal Indonesia (Kambing Kacang) dengan kambing Etawah. Kambing Etawah ini didatangkan dari India oleh Pemerintah Belanda pada sekitar tahun 1930 an. Kambing Etawah dikenal dengan ternak penghasil susu yang cukup baik. Akibat persilangan tersebut maka kambing PE sekarang ini juga memiliki potensi sebagai penghasil susu selain penghasil daging (Budiarsana, 2009).

Salah satu usaha untuk membantu perkembangan peternakan adalah dengan penyuluhan dan pelatihan kepada peternak kelompok Subur. Pelatihan ini diharapkan dapat memberi pengetahuan tambahan yang bermanfaat untuk meningkatkan produktifitas maupun manajemen pemeliharaan ternak. Lokasi pelaksanaan pengabdian masyarakat bertempat di Padukuhan Segajih, Desa Hargotirto kecamatan Kokap, Kulon Progo, Daerah Istimewa Yogyakarta, Indonesia. Jarak lokasi dari Universitas Gadjah Mada Yogyakarta kurang lebih $50 \mathrm{~km}$. padukuahan segajih merupakan bagian dari Desa Hargotirto yang memiliki luas luas wilayah 14.713,370 ha dan berpenduduk 8.337 jiwa. Secara umum wilayah Kecamatan Kokap berbukit sampai bergunung dengan ketinggian antara 500 - $100 \mathrm{~m}$ dpal ini memiliki tanah yang subur karena didukung oleh curah hujan $2.100 \mathrm{~mm} /$ tahun dan temperatur antara $23-28 \circ \mathrm{C}$.

Pusat pemerintahan kecamatan Kokap juga berlokasi di Hargotirto, yaitu beralamat di Jl. Ngaseman, Hargotirto, Kokap, Kulonprogo, 55653. Penduduk Desa Hargortirto mayoritas petani, peladang, pengrajin gula kelapa. Gula kelapa yang diproduksi di Hargotirto terbagi menjadi 2 jenis, yaitu gula jawa dan gula semut. Gula kelapa di Hargotirto diproduksi dalam skala rumah tangga. Selain sebagai pengrajin gula kelapa, penduduk Desa Hargotirto juga membudidayakan ikan air tawar dan keramba sebanyak 100 orang, peternakan kambing Etawa sebanyak 20 orang, peternakan kambing lokal 1.115 orang, peternakan sapi 10 orang, peternakan ayam 995 orang, produksi makanan tradisional 50 orang, produksi tempe 10 orang, budidaya jamur 5 orang, program PNPM Mandiri Pedesaan 1 unit. Lembaga Keuangan Mikro (LKM) 1 unit, industri kerajinan dan pertukangan 40 orang, dan kelompok Usaha Peningkatan Pendapatan Keluarga Sejahtera (UPPKS) 14 kelompok.

Tanaman perkebunan yang banyak ditanam adalah;

kakao, durian, salak, cengkeh, dan manggis. Potensi yang dimiliki oleh Desa Hargotirto terkait dengan pengembangan program Indonesia Sehat antara lain; Posyandu 16 kelompok dengan cakupan 48o anak, Yandu Lansia 14 kelompok dengan cakupan 240 orang, Desa Siaga 1 kelompok dengan sasaran seluruh ibu hamil, Tabungan Ibu Bersalin 1 kelompok, Persatuan Dukun Bayi 
Terlatih 1 kelompok. Desa Hargotirto memiliki potensi terkait dengan pelestarian hutan negara yang dilakukan oleh semua warga, budidaya Makutho Dewo dan tanaman herbal yang dikerjakan oleh hampir seluruh warga, budidaya durian lokal 15 orang, budidaya kakao (coklat) oleh hampir seluruh warga, produksi pupuk organik 200 orang, perkebunan dan pertanian organik 50 orang serta perkebunan salak pondoh 10 orang (RPJMD Kab Kulon Progo, 2014).

Permasalahan yang ditemui di masyarakat adalah akses jalan yang menanjak, kurang lebar dan cukup terjal. Sehingga akses transportasi sebagai sarana penghubung dan penggerak ekonomi kurang lancar. Informasi mengenai manajemen peternakan kambing belum memadai hal ini merupakan faktor penyebab hasil peternakan belum optimal. Tingkat pendidikan peternak kambing yang ditemui rata-rata memiliki tingkat pendidikan SD dan SMP. Kondisi-kondisi di atas bisa saja menjadi faktor yang menyebabkan daerah tesebut masih tertinggal dari daerah lain.

Kelompok ternak Subur sudah memiliki kandang kelompok yang dikelola bersama. Namun pengelolaan peternakannya masih tradisional, informasi mengenai reproduksi kambing, ilmu pakan ternak dan pengelolaan kambing yang baik belum di fahami secara optimal. Sehingga hasil yang diharapkan berupa induk bunting masih sedikit ( $5 \%$ dari populasi). Kelompok ternak Subur juga belum mengetahui teknik pengolahan produk susu maupun pengolahan limbah peternakan. Kendala pendanaan juga menjadi persoalan yang dihadapi oleh kelompok ternak.

\section{METODE}

Tahapan langkah langkah pengabdian kepada masyarakat ini diawali dengan mengadakan komunikasi dengan dokter hewan di daerah kecamatan kokap yang secara administratif membawahi urusan kesehatan kelompok ternak di wilayah tersebut. Selanjutnya dilakukan kunjungan ke lokasi peternakan kelompok bersama dokter hewan terkait. Kunjungan awal dan identifikasi masalah dilakukan pada bulan april 2017 bersama dokter hewan pendamping yang bertugas di daerah Kokap, Kulon Progo.

Pertemuan yang dilakukan dengan peternak menghasilkan beberapa poin yang dapat dijadikan sebagai informasi bagi pelaksanaan pengabdian kepada masyarakat. Poin tersebut antara lain: a). Telah di dapatkan lokasi pelaksanaan pengabdian kepada masyarakat yaitu di kelompok tenak Subur yang berlokasi di Dusun Segajih, Desa Hargotirto, Kokap, Kulon Progo. b) Kesediaan kelompok ternak Subur sebagai mitra kegiatan pengabdian kepada masyarakat 2017. c) Identifikasi permasalahan peternak kambing PE berhasil diperoleh dengan diskusi dengan peternak dan pengamatan langsung di lokasi kandang. d) Adanya komunikasi yang baik antara kelompok ternak Subur beserta dokter hewan di Puskeswan Kokap dan tim pelaksana kegiatan pengabdian kepada masyarakat Prodi Kesehatan Hewan Dept Teknologi Hayati dan Veteriner SV UGM

Metode yang ditawarkan dalam pengabdian masyarakat ini adalah dengan memberikan transfer informasi menganai manajemen reproduksi kambing. Pelaksanaannya dilakukan dengan pemberian materi dan diskusi secara interaktif sehingga anggota kelompok ternak dapat memahami dan memiliki kesempatan berdiskusi supaya lebih memudahkan penyampaian materi untuk difahami. Selanjutnya dilakukan praktek identifikasi tanda tanda birahi pada kambing betina dan pelaksanaan kawin alam apabila ada kambing yang siap untuk dikawinkan. Pemberian bantuan berupa vitamin dan mineral sebagai suplemen tambahan juga dilakukan dalam kegiatan ini. 


\section{HASIL KEGIATAN DAN PEMBAHASAN}

Pelaksanaan pengabdian kepada masyarakat dilaksanakan pada tanggal 13 Mei 2017 bertempat di rumah Bp. Basuki sebagai ketua Kelompok Ternak Kambing PE "Subur". Pelaksanaan berjalan dengan lancar diawali dengan pemaparan materi manajemen reproduksi kambing PE oleh drh. M. Rosyid Ridlo, M. Sc. yang menekankan bagaimana mendeteksi atau mengenali gejala-gejala yang muncul pada kambing yang siap kawin. Matri lainya yang disampaiakan adalah pentingnya penguatan manajemen reproduksi yang akan menyokong keberhasilan peternakan kambing perah sebagai penghasil susu kambing. Materi ke-dua disampaikan oleh drh. Yohanes Wawan Budiyanto yang menjelaskan mengenai kesehatan hewan dan penanganannya. Peserta sangat antusias mengikuti kegiatan dengan banyaknya pertanyaan dan menyampaikan keinginannya agar kegiatan ini dapat dilaksanakan dengan teratur. Hal ini sangat baik dilakukan agar pelaksanaan pembinaan kepada mitra dapat berlangsung secara berkelanjutan, apabila ada permasalahan segera ditemukan solusi yang terbaik. Kegiatan yang berlangsung secara berkelanjutan diharapkan dapat memantau perkembangan setiap tahapan yang dilalui peternakan kambing PE.

Praktek pengamatan tanda birahi dan pengenalan kambing betina yang mengalami birahi dan tidak birahi juga dipraktekkan secara langsung. Peternak dapat melihat secara langsung bagaimana ciri-ciri hewan yang estrus. Pengenalan hewan estrus/birahi sangat penting karena kondisi kandang yang bertipe batre hanya berisi kambing betina saja baik berkelompok atau individu. Hal ini apabila tidak diamati dengan baik maka waktu birahi akan terlewat sehingga perkawinan menjadi tertunda. Keadaan ini jika tidak segera diubah akan berakibat pada pengunduran waktu kebuntingan dan kelahiran. tidak adanya kelahiran dalam sebuah peternakan tentu akan berdampak pada ketiadaan produsi susu. hal ini akan menjelaskan bahwa manajemen reproduksi sangat penting dalam keberlangsungan peternakan kambing perah.

Berdasarkan hasil analisis penelitian menjelaskan bahwa dalam skala besar produksi susu yang harus dicapai agar perusahaan tidak mengalami kerugian yaitu pada saat perusahaan menghasilkan susu sebanyak 77.50o liter atau harga susu Rp. 17.400/liter. Dengan menggunakan modal sebanyak Rp. 565 juta maka semua modal yang digunakan akan dapat kembali pada periode usaha 2,6 tahun. Analisis internal rate return menunjukkan nilai sebesar 27,91\%. Nilai ini lebih besardibandingkan dengan nilai tingkat suku bunga yang berlaku di pasaran (Bank). Dengan demikian dapat dikatakan usaha ini profitable dan layak untuk dilakukan (Budiarsana, 2009).

Evaluasi pelaksanaan dilakukan pada tanggal 20 Juli 2017 setelah pelaksanaan penyuluhan dan praktek sosialisasi manajemen reproduksi. Hal hal yang dievaluasi antara lain: a) Peran aktif anggota kelompok dalam recording pengamatan birahi. b) Jumlah kambing yang ditemukan estrus, c) Kambing yang dikawinkan. Berdasarkan evaluasi di lapangan akan dilakukan pembahasan untuk tindak lanjut pelaksanaan kegiatan pengabdian kepada masyarakat pada periode selanjutnya.

Betina yang menjadi induk sangat penting untuk diperhatikan genetic keturunannya. Keturunan dari induk yang berkualitas baik akan menurunkepada anaknya. Latar belakang garis keturunan akan berperan penting untuk membentuk kualitas dari kambing perah dalam sebuah peternakan. Hal ini juga bisa menjadi strategi bagi peternak dalam mengawinkan induk betina supaya selektif dalam memilih pejantan (Shrestha dan Fahmy, 2005)

Pelaksanaan monitoring diawali dengan diskusi bersama peternak mengenai perkembangan peternakan yang telah dilaksanakan. Peternak telah melakukan pengamatan deteksi birahi setiap hari. Pengamatan dilakukan dengan cara visual dan menggunakan pejantan sebagai detektor estrus alami. Peternak dapat 
membedakan betina estrus dengan mengamati perubahan mucosa vagina, dan tingkah laku kambing betina. Kebuntingan yang dapat teramati juga menjadi lebih banyak, pada awal pertemuan pada saat inventarisasi permasalahan kambig yang bunting berjumlah dua ekor, sedangkan pada saat monitoring evaluasi kambing yang dijumpai ditemukan sebanyak sebelas (11) ekor kambing betina yang bunting. Penampakan kesehatan dan rambut kambing juga terlihat lebih baik dengan penampakan lebih mengkilap. Hal ini menunjukkan bahwa dengan penambahan pakan dan pemberian vitamin mampu meningkatkan performa kesehatan kambing.

Pengamatan waktu birahi sngat penting untuk dilakukan. Hal ini karena pada saaat hewan mengalami estrus, secara fisiologis kambing betina mengalami perkembangan ovulasi yang sudah mencapai folikel de graaf. Folikel de graaf merupakan fase puncak dari fase folikuler yang mana tahapan selanjutnya adalah pelepasa sel telur dari folikel yang disebut sebagai ovulasi. Seteleh sel telur dilepaskan maka sel telur akan siap untuk proses fertilisasi/pembuahan. Saat inilah waktu yang tepat untuk perkawinan. Oleh karena itu pada saat kambing betina mengalami ovulasi dan siap untuk fertilisasi maka tanda tanda estrus/birahi juga muncul. Kejadian estrus hanya terjadi 2-3 hari, apabila peternak terlewat mengamati dan mengawinkan kambing betinanya maka kesempatan untuk bunting menjadi hilang. Peternak harus menunggu satu siklus reproduksi kira-kira 18-20 hari ke depan (Medan, et al., 2005).

Hasil pengabdian kepada masyarakat dalam bentuk penyuluhan dan pelatihan memberikan capaian yang positif tehadap peleksanaan peternakan kambing PE. Capaian yang diperleh antara lain: Peternak telah memahami dan melakukan pengamatan deteksi birahi setiap hari. Pelaksanaan pengamatan dilakukan oleh petugas yang telah ditunjuk dari anggota kelompok ternak. Pengamatan dilakukan dengan cara visual dan menggunakan pejantan sebagai detektor estrus alami: 1) Peternak dapat membedakan betina estrus dengan mengamati perubahan mucosa vagina, dan tingkah laku kambing betina. 2) Kebuntingan yang dapat teramati juga menjadi lebih banyak, pada awal pertemuan pada saat inventarisasi permasalahan kambig yang bunting berjumlah dua ekor, sedangkan pada saat monitoring evaluasi kambing yang dijumpai ditemukan sebanyak sebelas (11) ekor kambing betina yang bunting. 3) Penampakan kesehatan dan rambut kambing juga terlihat lebih baik dengan penampakan lebih mengkilap. Hal ini menunjukkan bahwa dengan penambahan pakan dan pemberian vitamin mampu meningkatkan performa kesehatan kambing. 4) Terjalinnya komunikasi antara peternak dan institusi pendidikan, dalam hal ini adalah Prodi Kesehatan Hewan Departemen Teknologi Hayati dan Veteriner Sekolah Vokasi UGM. 5) Peternak kelompok ternak dapat berkonsultasi dan diskusi mengenai pengembangan peternakan atau permasalahan ternak melalui komunikasi via telephone atau media sosial. 6) Prodi Kesehatan Hewan Departemen Teknologi Hayati dan Veteriner Sekolah Vokasi UGM memiliki akses terhadap dokter hewan di wilayahKokap, mitra peternak kambing PE, pengrajin Gula kelapa, petani salak yang bisa untuk diadakan kerjasama di masa mendatang.

Kegiatan yang baik ini hendaknya dilakukan secara terus menerus. Keberlanjutan kegiatan sangat baik utuk dilaksanakan mengingat pendampingan kepada peternak dalam rangka pengembangan peternakan sangat dibutuhkan. Kelompok ternak Subur tergolong masih pemula sehingga masih perlu banyak perbaikan dalam hal manajemen pemeliharaan, pakan, reproduksi, pengolahan hasil ternak, pemasaran produksi dan hal yang terkait dengan perijinan. Sehingga program pengabdian masyarakat yang terus berlanjut akan memberikan dampak positif yang nyata dalam pengembangan peternakan, ekonomi dan sosial masyarakat kelompok 
ternak Subur di Dusun Segajih, Desa Hargotirto, Kecamatan Kokap, Kabupaten Kulon Progo, DIY.

\section{SIMPULAN}

\section{Simpulan}

Sosialisasi reproduksi memberikan dampak yang baik terhadap peternak dan ternak kambing PE. Kegiatan Pengabdian kepada masyarakat di Kelompok Ternak Subur Hargotirto. Kokap. Kulon Progo memberikan manfaat terhadap peternak maupun Universitas Gadjah Mada dan Pemerintah Kabupaten Kulon progo pada umumnya.

Saran

Pelaksanaan Pengabdian Kepada Masyarakat, diskusi dan penyuluhan lanjutan akan sangat baik dilakukan secara berkelanjutan pada kelompok ternak yang sama supaya diperoleh kemajuan yang terpantau dan terencana. Prioritas ke depan antara lain membangun sarana pengairan/sumur untuk memudahkan pemberian minum ternak dan manajemen reproduksi lanjutan.

\section{DAFTAR PUSTAKA}

Budiarsana I.G.M. (2009). Ekonomi Usaha Ternak Kambing PE sebagai Ternak Penghasil Susu dan Daging (Economic Analysis Of PE Goat as Milk and Meat Producer in a Farming Sytem). Seminar Nasional Teknologi Peternakan dan Veteriner 2009.

Medan M.S., Watanabe G., Sasaki K., Groome N. P., Sharawi S., Taya K. (2005). Folicular and Hormonal Dynamics during the Estrous Cycle in Goats. Journal of Reproduction and Development. Vol 51. No. 4, 2005.

Rencana Pembangunan Jangka Menengah Daerah (RPJMD) Kabupaten Kulon Progo Tahun 2011-2016. (2014). Pemerintah Kabupaten Kulon progo. [22 Maret 2017].

Sada. (2012). Plan for kulon progo. https://sadastudio.wordpress.com/pe ta/. Online 2012. [22 Maret 2017].
Shrestha J. N. B. dan Fahmy M.H. (2005). Breeding goats for meat production: a review. Genetic resources, management and breed evaluation. Small Ruminant Research 58 (2005) 93-106. 